\title{
JOURNAL.RU
}

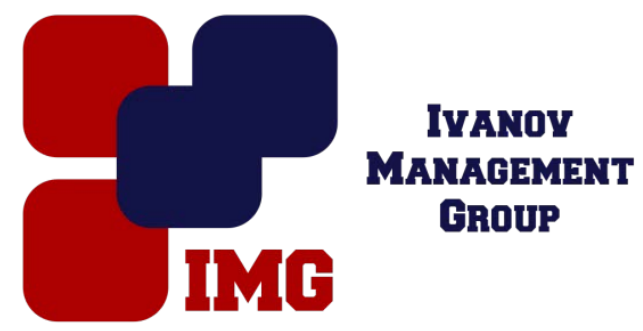

Свиридова И.В., Лебединская А.А., Внукова 3.А., Кичигина А.К., Зайцева Т.В. Белгородский государственный наииональный исследовательский университет Белгород, Россия

doi: 10.18411/lj-31-01-2017-1-10

idsp 000001:lj-31-01-2017-1-10

\section{Разработка информационной подсистемы логистики на примере ООО ТД «Малахов +»}

Логистика - это процесс создания оптимальной инфраструктуры движения товаров и услуг от поставщиков к потребителям [1].

Анализ работы логистов в России показывает, что наиболее профессионально важными для них являются знания и умения поиска информации, а также отбора и обработки приобретенных сведений, необходимых и достаточных для деятельности любого без логиста. Чтобы на должном и высоком уровне решать поставленные перед ним задачи, необходим соответствующий инструментарий и методология внедрения данного информационного обеспечения, в связи, с чем высока роль персонального компьютера как инструмента, обеспечивающего эффективность работы с данными, и современных технологий хранения и поиска информации [3].

При разработке информационной подсистемы логистики целесообразнее всего нужно описать систему «КАК ЕСТЬ» и «КАК ДОЛЖНО БЫТЬ». На рисунке представлена контекстная диаграмма «КАК ЕСТЬ».

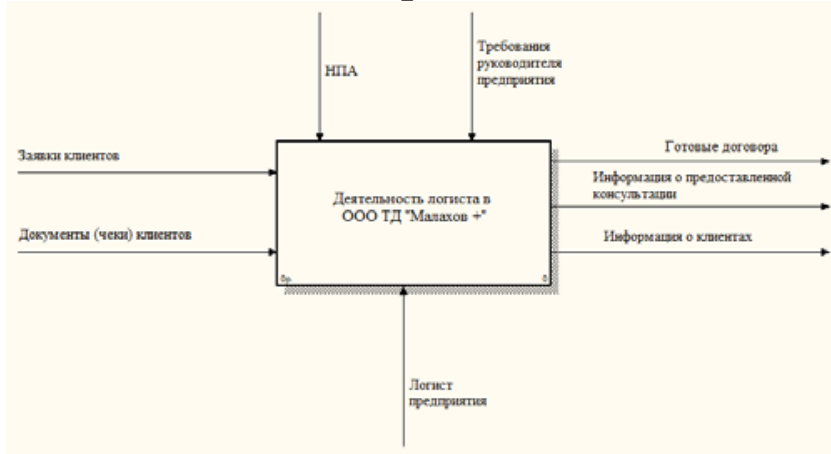

Рисунок 1 - Контекстная диаграмма «КАК ЕСТЬ»

Для решения данных проблем необходимо автоматизировать рабочее место логиста, так как это позволяет более удобно и быстро выполнять необходимые операции. Так же необходимо проводить действия по 
привлечению клиентов в ООО ТД «Малахов+», это позволит увеличить рост прибыли в компании.

Основной целью оптимизации и регламентации реинжиринга является качественное улучшение деятельности компании, а также отдельных еe направлений за счет создания взаимосвязанного комплекта системообразующих документов, которые описывают наиболее значимые (ключевые) и часто реализуемые процессы [2].

На следующем рисунке представлена контекстная диаграмма «КАК ДОЛЖНО БЫТЬ» работы конфигурации «Деятельность логиста ООО ТД «Малахов +».

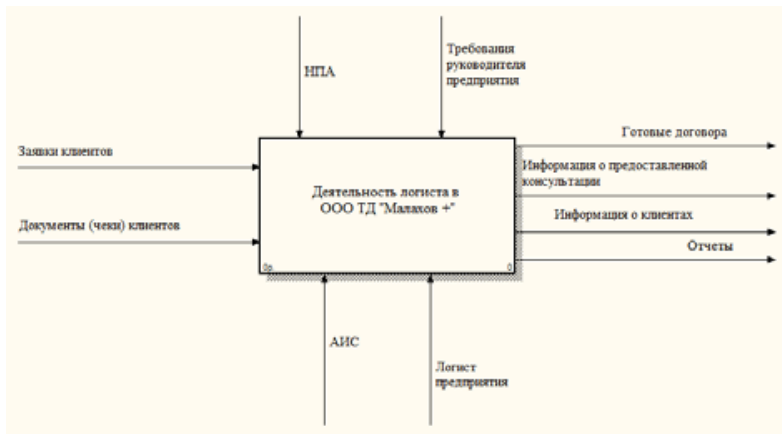

Рисунок 2 - Контекстная диаграмма «КАК ДОЛЖНО БЫТЬ»

В связи с удобством конвертации данных из электронных таблиц в систему 1C: Предприятие было принято решение разрабатывать собственную конфигурацию на встроенном языке программного продукта и создать специфические для ТД «Малахов+» виды отчетов.

Была разработана собственная конфигурация на платформе $1 \mathrm{C}$ : Предприятие 8.2 с использованием встроенного языка программирования 1С: Предприятие.

На основе спроектированной функциональной модели системы были созданы и настроены все необходимые объекты конфигурации. Система готова к использованию.

Был создан отчет, формирующий остатки товаров на предприятии в целом и по каждому ответственному сотруднику. Это позволяет эффективнее контролировать деятельность сотрудников.

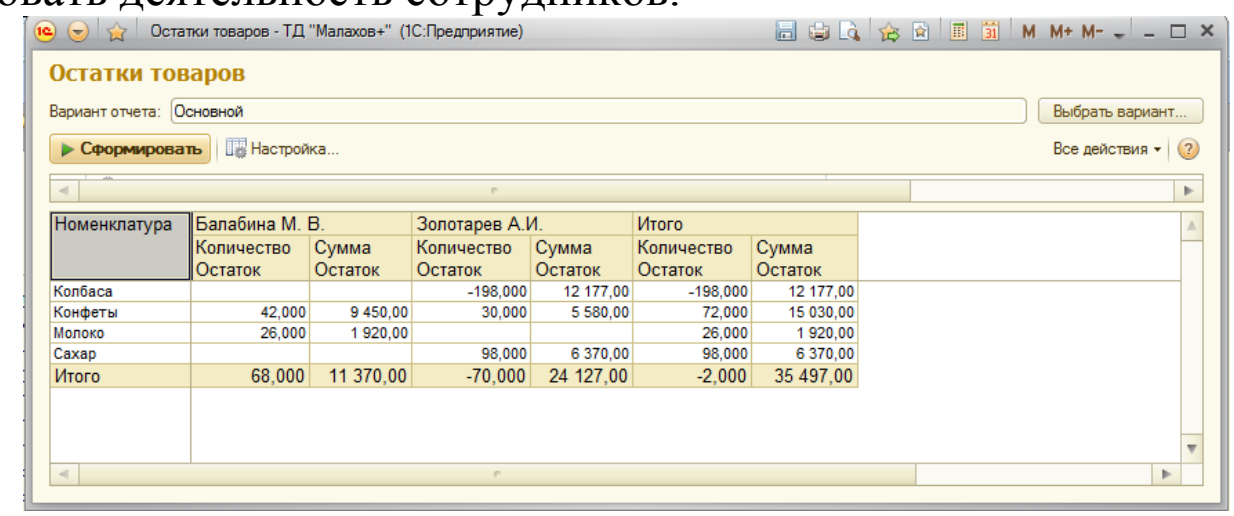

Рисунок 3 - Отчет по остаткам товаров 
Еще один разработанный отчет показывает движение товаров на предприятии. Также он отображает движение товаров по отдельным сотрудникам. С его помощью намного упрощается процесс учета товаров.

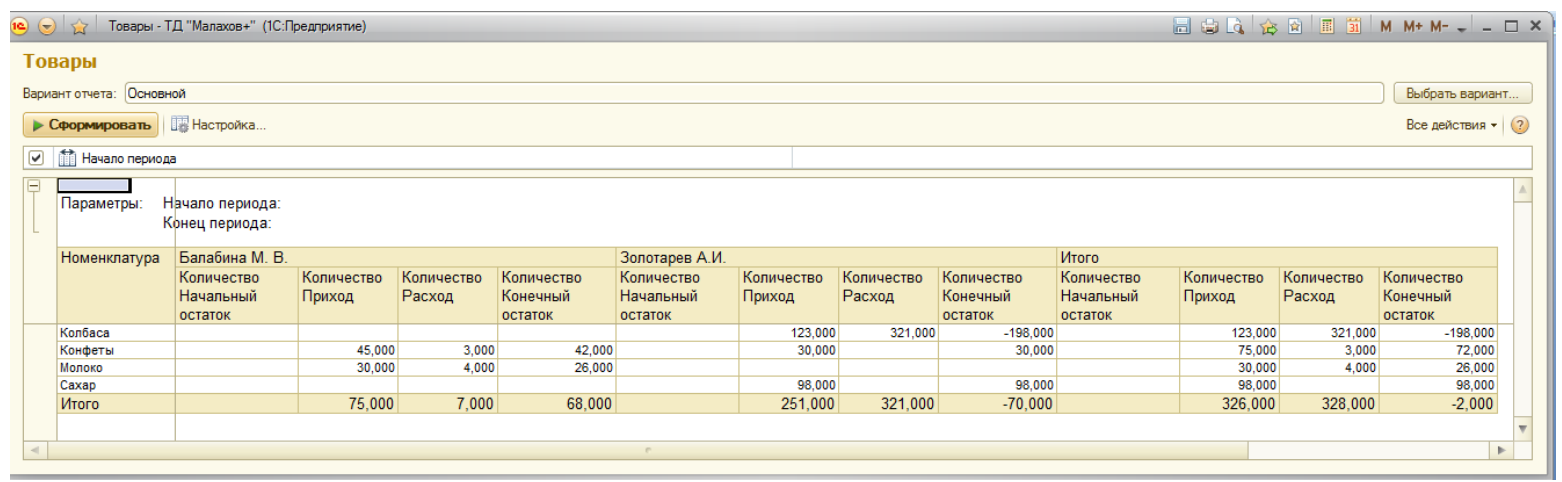

Рисунок 4 - Отчет по товарам

Разработанная автоматизированная подсистема позволяет повысить оперативность и производительность логистов. За счет систематизации данных, система позволяет увеличить скорость и качество их работы. Разработанная система позволила синхронизировать используемые данные и сократить бумажные архивы. Данная конфигурация обладает интуитивно понятным интерфейсом, что упрощает работу с ней даже начинающим пользователям. Это ещё раз подчёркивает привлекательность этого решения ведения учёта.

\section{Литература}

1. Логистика и управление цепями поставок: учебник для академического бакалавриата / под ред. В. В. Щербакова. - М.: Юрайт, 2015. 582 с.

2. Радченко М.Г., Хрусталева Е.Ю. 1С Предприятие. Практическое пособие разработчика - М.: ООО «1С-Паблишинг», 2009 - 857 с.

3. Хомичевская В. Переходим на 1С: Бухгалтерию. ИД "Питер - 1C: Библиотека - 2007, 496 с. 